\title{
Foot and Facial Reflexology: History and Healing Powers
}

\section{Anne Hilarius-Ford*}

Foot and Face Reflexologist, Energy Reflexology, Port Melbourne, Australia

*Corresponding Author: Anne Hilarius-Ford, Foot and Face Reflexologist, Energy

Reflexology, Port Melbourne, Australia.

DOI: $10.31080 /$ ASMS.2020.04.0560
Received: January 09, 2020

Published: February 10, 2020

(C) All rights are reserved by Anne

Hilarius-Ford

\section{Abstract}

The article is about the historical practice of Foot and Facial Reflexology. Modern day Reflexology evolved through observation, practice and research. Using the application of modern medical equipment and science, the relationship between reflexes on feet and face were shown to influence the brain and the reflected organ. Detailed records on techniques and number of treatments show how and when healing happened.

Keywords: Healing; Foot; Facial Reflexology

The origins of reflexology

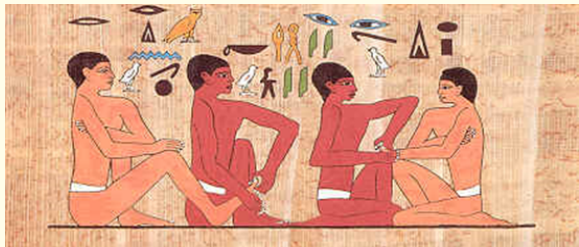

Figure 1

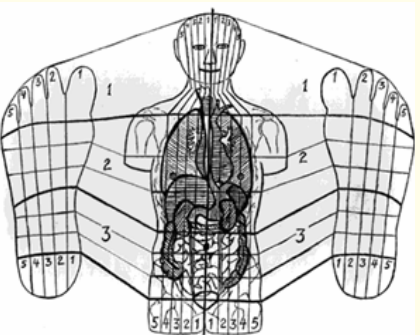

Figure 2
Across ancient times, different tribes and cultures have found ways to support health by working on the feet and face.

In Ancient Egypt, Ankhm'ahor's tomb shows depictions where hands and feet are worked. This tomb is also known as the physician's tomb, at Saqqara in Egypt.

The translation of the hieroglyphics are as follows:

- "Don't hurt me".

- The practitioner's reply: "I shall act so you praise me".

In China in $4000 \mathrm{BC}$ there are accounts that describe pressure was applied using fingers and thumbs. Early books describe 'examining foot method' and this was before acupuncture needles were considered.

Indian tribes in North America observed a form of foot therapy for 100 's of years.

\section{Modern day reflexology}

Still today, we learn about longitudinal zones on feet and hands where organs in the same zone are connected. This visual map helps practitioners to locate reflections of organs on feet and hands. Dr. William H. FitzGerald, M.D, an Ear, Nose, Throat specialist [1], was the creator of this insight. This concept is known as Zone Theory and is the foundation of modern Reflexology.
Dr. Shelby Riley, M.D. working closely with Dr. FitzGerald and learning about his concept of longitudinal zones, added horizontal zones across hands and feet. This new map clearly makes it easier to find individual reflexes.

As Dr. FitzGerald worked specific points on toes and hands, he noticed patients were able to endure small operations on nose and throat without needing an anesthetic. Always observant on how his patients experienced procedures, he couldn't help but notice that not only was there pain relief from the procedures, but the primary cause was also addressed.

Seeing these results, Dr Bowers urged Bruce Barton, editor to Everybody's Magazine, to publish an article on Dr FitzGerald's Zone Therapy. As happens with new discoveries, Bruce Barton didn't believe anyone would be interested in reading about this. He even assumed no one would accept there were any healing outcomes. He eventually decided to visit Dr FitzGerald's rooms and was astounded to see patients experienced real benefits such as:

- Patients cured of goitre

- Throat and nose troubles eased immediately

- Nose operations made without an anaesthetic

- $\quad$ Teeth pulled without an anaesthetic.

The common technique used was Zone Therapy. After witnessing these feats, Bruce Barton published Dr Bowers article on Zone Therapy. This was the first one ever written on this new field. 
Eunice D. Ingham



Figure 3

Eunice D. Ingham was a Physiotherapist who worked with Dr. Riley. Intrigued with Zone Therapy after seeing results of the work he did, she started her new journey in the early 1930's. As she worked with hundreds of patients, she recorded her findings with detail. She checked and double checked every reflex she worked with how the patient felt and reacted over a period of time. This thorough work allowed her to determine with confidence that the reflexes on the feet were the exact reflection of all the internal organs in the body [1].

It was Dr. Riley who inspired her to write her first book, "Stories the Feet Can Tell". Here she documents the cases she worked with. She used her scientific background to precisely map out the reflexes on the feet and this is what we still work with today.

It was first published in 1938 and was later translated into seven languages. This says a lot about her thorough work. Her detailed work and book spread the benefits of Reflexology beyond the US.

Today there is a little confusion between what is known as Reflexology and Zone Therapy. The publisher of the translated books changed the title from " The Stories the Feet Can Tell" to "Zone Therapy". There is a clear difference between the two though. Zone Therapy looks at the zones on the feet to locate the area to work with. Reflexology on the other hand, considers both the zones and the physical anatomy to select the area or areas to work with.

Eunice Ingham, passionate about her work, shared her knowledge about Reflexology by travelling the world until the age of 80 . She never wavered around her conviction that Reflexology is a great tool to support health. She died in 1974, aged 85.

\section{Family business}

Dwight Byers and his sister Eusebia Messenger, RN, understood the benefits of what their aunt worked on and in the late 50's they supported her work.

In the mid 70's, Dwight founded The International Institute of Reflexology ${ }^{\circledR}$. The Institute represents the essence of Eunice's work and tirelessly keeps working on the Reflexology theories and

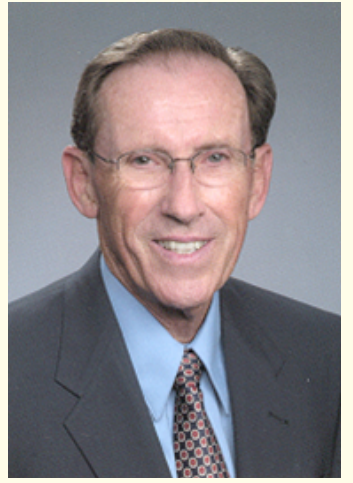

Figure 4

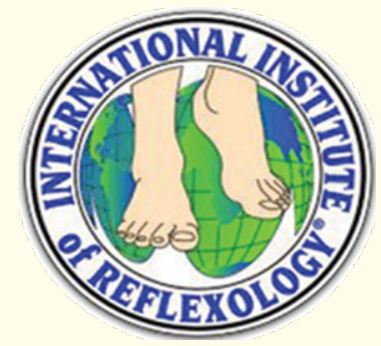

Figure 5

techniques. Throughout, Dwight Byers has shown the same perseverance and devotion as his Aunt Eunice Ingham by promoting Reflexology across the world. He is a leading authority on Foot Reflexology.

Together with a trusted team of instructors, Mr. Byers, director of the International Institute of Reflexology ${ }^{\circledR}$, continues to conduct workshops around the world, teaching both practitioners and those interested.

Examples of reflections of the body on the feet
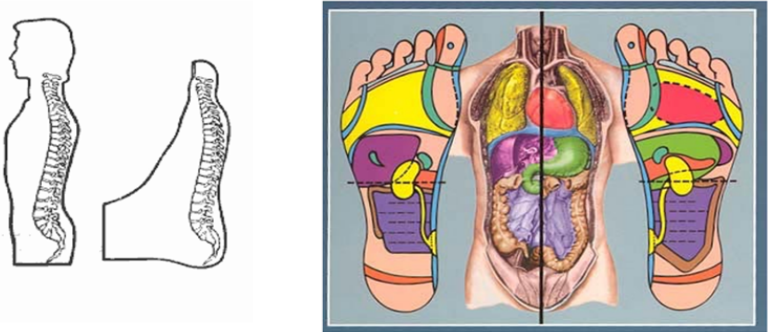

Figure 6

Research

Functional magnetic resonance imaging: reflexology in action

fMRI was used to study how stimulating a Reflexology reflex affected the reflected organ. Three reflexes were worked, and it was found that a somatosensory process corresponding to the stimulated reflex area was produced. It was clear there was a connection between the reflex and the organ [2]. 


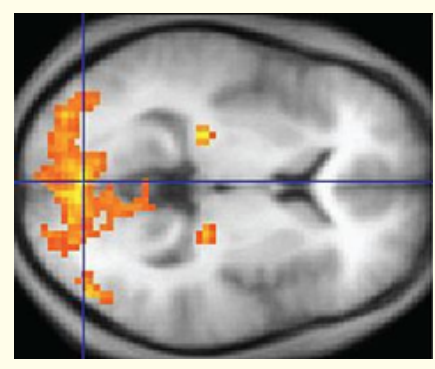

Figure 7

Doppler ultrasound of the kidney

A Doppler ultrasound was used in research as the kidney reflex was worked on the foot. Changes in renal blood flow became apparent using this technology.

Doppler sonography, a non-invasive technology, helps to uncover structural changes and gives information on the direction of flow in renal vessels. Narrowing of blood vessels can also be identified through several Doppler criteria [3].

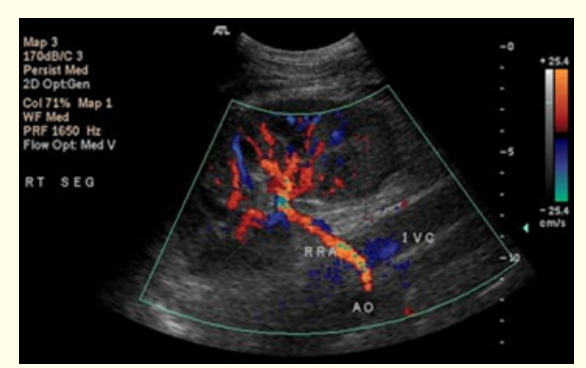

Figure 8

\section{Dr Jesus Manzanares}

Dr. Jesus Manzanares, M.D. [4] graduated in Medicine and Surgery at the Autonomous University of Barcelona in 1982. He specializes in family medicine integrating homeopathy and reflexology with conventional medicine. Intrigued by reflexology, he conducts his own research and discovered a Neurophysiological Basis for Reflexology [5].

As a Reflexologist works the feet, some areas feel different to others. To the touch, some areas seem to have deposits whilst others feel clear. Dr Manzanares took biopsies from both deposit and non-deposit tissues, analyzed them and the results showed a clear difference between them. He tried to understand the role of the nervous system in reflexology. The result of the test was significant as it showed more nerve fibers in the deposit tissue. This shows an imbalance (anatomical or functional) of the organ or body part represented in the corresponding reflex area in the foot.

With his scientific and medical training, Dr Manzanares was intrigued by his findings using Reflexology on patients and his research in the field began, focussing on three primary objectives. He succeeded to:

- Explain the neuro-physiological source (the nervous system pathways for reflexology)
- Determine the precise anatomical position of the reflex areas on the feet, elaborating on the precise foot-to-body connection, work done over 27 years on 70,000 clinical cases.

- Establish reflexology protocols for pathologies.

\begin{tabular}{|l|l|}
\hline \multicolumn{1}{|c|}{ Non-deposit Tissue } & \multicolumn{1}{c|}{ Deposit Tissue } \\
\hline $8 \%$ nervous fibers & $42 \%$ nervous fibers \\
\hline $27 \%$ vascular elements & $28 \%$ vascular elements \\
\hline $65 \%$ connective tissue & $30 \%$ connective tissue \\
\hline
\end{tabular}

Table 1

Reflexology lymphatic drainage (RLD) - sally kay BSc (Hons)

Reflexology Lymph Drainage stimulates the lymphatic system. This enables lymphatic fluid to flow to the lymph nodes so that waste materials and excessive fluid can be flushed [6].

At Cancer Care clinics, many of the women treated for breast cancer experienced secondary lymphoedema. Sally used reflexology and patients shared they could feel tingling in the affected arm as the feet were worked. Clothing and jewelry were loser as there was reduced swelling. Sally had a basic understanding of Manual Lymphatic Drainage (MLD) which led her to successfully transfer the concept on the reflection of the body on the feet. Research was then conducted which reinforced the theory of reflexology.



Figure 9

The aim of the research [7] was to examine how RLD could benefit breast-cancer related lymphoedema. The arm was measured before and after each treatment which visibly showed considerable reduction in the fluid volume in the affected arm. This decrease in volume was maintained for more than six months. Quality of life for the participants improved as there was reduced pain, weakness and limitations in everyday activities. Instead, there was increased comfort and mobility. No serious adverse effects were reported.

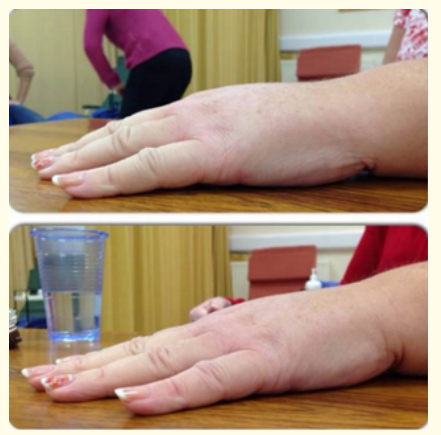

Figure 10 


\section{Origins of facial reflexology}

Facial Reflexology has its origins in Auricular Therapy and has over time developed in an effective therapy.

Auricular therapy



Figure 11

Auricular Acupuncture is a diagnostic tool. It is effective in treating many physical, emotional and mental conditions. It has been used throughout Europe and Asia for thousands of years.

From 1951 Dr Nogier, a French medical doctor, started using acupuncture on the ear and his patients experienced pain relief. Through these experiences, it became clear to him how the body is projected on the ear lobe and in 1956 he presented the image of the inverted foetus on the ear lobe. His work confirmed that conditions could be healed working the ear [8].

Seeing Nogier's ear reflex system, the Chinese used his knowledge and incorporated this with Traditional Chinese Medicine (TCM) theories. To this day, they still call Dr Nogier the 'Father of Auriculotherapy'. From then on, the Chinese used this knowledge to detox opium addicts.

Auricular Therapy has developed further. Dr Terry Oleson, $\mathrm{PhD}$ in Psychobiology, conducted pioneering research on auricular diagnosis and auricular acupuncture. Today it is used by many complementary modalities such as by reflexologists, chiropractors, acupuncturists, etc. [9].

Dien Chan

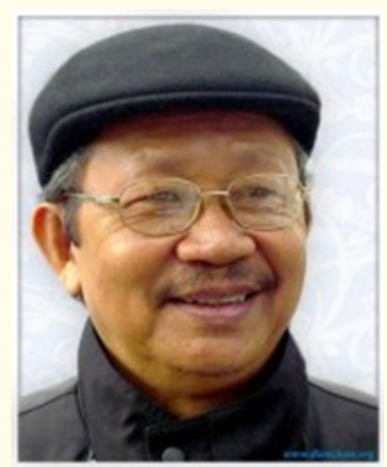

Figure 12
Professor Bùi Quôc Châu, a Vietnamese Professor in Acupuncture, treated many opium addicts in Vietnam following the work done by Dr Nogier and the use of it in TCM.

In 1980, the use of auricular therapy led him to discover the start of a captivating practice he named Dien Cham. Still using acupuncture needles, he realizes from 1982 these were not required. This is when he renamed the practice Dien Chan [10].

The name he chose reflects the practice. Dien means 'face and surface', Cham means 'prick with a needle' whilst Chan means 'facial treatment and diagnostic'. Professor Bùi Quôc Châu is grateful to Dr Nogier as his work clearly showed him the irrefutable relationship between face and body and lead him to find comparable projection systems [10].

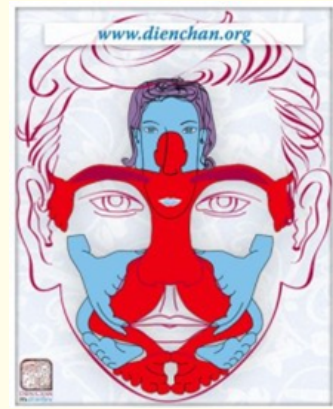

Figure 13

From the start Professor Châu looks at the hypothesis of analogy. Looking at the curve of the nose he 'sees' the spine and that it can be treated on the nose. This is validated when a patient experienced immediate pain relief when pressure is used on the reflection. This was repeated with great success. Professor Châu discovers twenty-two projection systems of the body on the face and 257 fixed points. Professor Châu sees Dien Chan as complementary to both Oriental and Western medicine.

The therapy reaches the USA in 1985, France in 1992 and Spain in 2001. There Patryck Aguilar-Cassarà and Anna Roca record the method on behalf of Professor Bùi Quôc Châu [15]. In 1988 Professor Châu gave a series of seminars in La Havana with the result that the entire Cuban network of Public Health adopts Dien Chan officially. Doctors use it and call it Terapia Cibernética. Today it is called Dien Chan, multireflexology BQC to honour its founder.

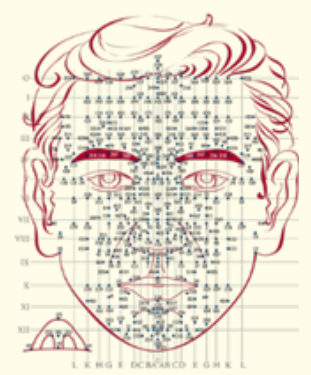

Figure 14 
Working with many patients, Professor Bùi Quôc Châu trialled the method by stimulating various combinations using specific points in a set order. The great results he saw helped him create treatment formulas. These are only suggestions as the combination of points used in treatment is not limited. New combinations are still being discovered.



Figure 15

The multireflexology method relies on combining the projections of the body on the face and the points during a treatment. These correspond to an organ and/or a zone and working them together helps direct Qi energy to the weakened organ. Working only one of these systems reduces the multireflexology method.

The projections and points on the face are a direct link to the brain, not the physical body. This means that stimulating zones or points on the face triggers self-regulation of the corresponding organ in the brain. The energy is then channelled to the corresponding affected organ or zone.

Patryck Aguilar-Cassarà has developed FACEASiT, an application for the iPad. FACEASiT offers solutions and helps the practitioner to design a treatment based on the part of the body that needs attention. It is a natural methodology that supports health [16].

\section{Marie France Muller}

Marie France Muller is a doctor in psychology and naturopathy as well as a reflexologist. When her teacher Nhuan Le Quang told her about Dien Cham she was very sceptical as she couldn't believe it could relieve any pain, sometimes permanently, just working on one or more points on the face.

It is only after she experienced the benefits herself as feeling in 'dead' fingers returned that she registered to attend the course. The next day, at her dentist's surgery, someone had severe sciatic pain. Still fresh from her learnings, she couldn't remember any points on the face but in her mind's eye could see the body's projections on the face. This allowed her to relieve the severe pain with four successive short sessions. Amazed by this result, she wrote a book as she was determined the technique needed to be promoted. In her book she gives clear protocols to work specific conditions [17].

\section{Lone Sorenson}

Lone Sorenson was part of the very first wave of Reflexologists in Denmark, she qualified in 1978 when she was only 18 and registered as number 59 in Denmark. There are now over 12.000 reflexologists in Denmark. Until 1988 she mostly worked with children who had learning and behavioural difficulties and studied cranial therapy to support them further. In 1988 she moved to Argentina where spent 12 very productive years. The first reflexologist in that country, she treated patients with brain damage and neurological problems. She also opened three schools training 2000 reflexologists.

Dr Wong, a Chinese doctor, invited Lone to visit Argentina and he explained about acupuncture points on the face and taught her 16 of them, each point activating 3 systems in the body. These NP points are close to the brain and she used them with great success in her clinic in Denmark. She decided to move to Argentina where her reputation grew quickly. A local man who was very poor had leg ulcers that had been wrapped up in plastic for 30 years. Knowing she could help, the ulcers were healed after ten treatments, and the word spread.

On one of her trips inland she saw tribal South American Indian women use a facial stimulation technique that was not a face massage. She received permission to take notes and make drawings of what she saw.

Back at her clinic Lone saw a 23-year-old young woman who had acquired brain damage from a car accident she was involved in three years earlier. Eight treatments using foot reflexology alone showed no change. With her permission, Lone used the facial techniques she had observed the tribal women use, and within ten minutes the young woman's whole body relaxed. Lone had never experienced anything like it and went on to treat her three times a week using foot and face reflexology as well as the new techniques learned from Dr Wong and the tribal women. After a year, this young woman was $97 \%$ cured.

Working with this client was the start of lone's facial reflexology therapy

Travelling to Cuba several times, Lone studied the Dien Chan treatment method. She learned a system using nerve points and 31 acupressure points in the face. With her inquisitive mind, she combined this with the what she learned from the South American Indian women. She met Dr Chun, a Vietnamese doctor. Dr Chun worked with the oriental system of charting the face to reflect body organs and systems, Lone incorporated his methods and experience into her treatments.

During her career, Lone studied many modalities in many countries. These include reflexology, kinesiology, acupuncture and facial acupuncture, oriental medicine, auricular therapy, vibrational therapy as well as neurology and anatomy in countries as varied as Cuba, France, Spain, Germany and Argentina. Ever since she qualified in 1978, Lone was never satisfied with what she knew then. Throughout, she absorbed practical experience, studied, researched and tested various theories.

All these techniques became part of Facial Reflexology SorensensistemTM.

If that was not enough, she developed new therapies for braindamaged children. With a system called Stimulation Temprana 
(early stimulation) Lone has achieved excellent results and published a video showing an example of such results [13]. Through the development of the Temprana Reflex Therapy - where Lone teaches parents to work daily on their children using facial, neurological reflexology and neurological hand reflexology - the emphasis changed to using $80 \%$-facial reflexology and $20 \%$-foot reflexology during a treatment.

She has also helped coma patients, and people with such conditions as Multiple Sclerosis, Downs Syndrome, and Motor Neuron Disease; the more serious the disease or condition, the more intense the treatment.

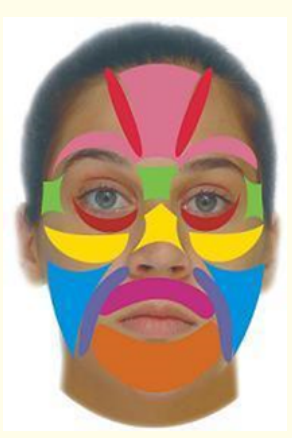

Figure 16

Today she lives in Barcelona where she still teaches at her school as well as at the Medical Faculty at the University Complutense in Madrid [18].

Her current method of facial reflexology and face mapping has been developed over twenty-eight years of work with clients and combines various techniques to provide a holistic and comprehensive treatment.

A treatment includes various steps that work projections of the body on the face as well as neurological points. This helps to personalize the treatment for the client's health condition. The last phase is a gentle face massage that balances the mental, physical and emotional aspects.

Sue Ehinger, certified teacher of Lone's Facial Reflexology method, mentions: 'over the past seven years working with Facial Reflexology techniques, I have renewed my passion for our therapy and have developed a deep respect for the pioneering work of Lone Sorensen. The therapy is awesome, and the results speak for themselves' [14].

Facial reflexology acts on the central nervous system and brain whilst foot reflexology acts on the blood/circulation and releasing hormones in the blood [12].

\section{Conclusion}

History and research show the health benefits of the application of pressure on reflexes on feet and face. The ancient methods working on feet and face developed through tribal wisdoms when natural and available methods were used to support health and wellbeing. Widely used today, research shows Reflexology and Auricular therapies are beneficial for health management.

\section{Bibliography}

1. International Institute of Reflexology. "History of Reflexology".

2. Nakamaru., et al. "Somatotopical relationships between cortical activity and reflex areas in reflexology: A functional magnetic resonance imaging study". Science Direct 448.1 (2008): 6-9.

3. Sudmeier I., et al. "Changes of renal blood flow during organassociated foot reflexology measured by color Doppler sonography". Forsch Komplementarmed 6.3 (1999): 129-134.

4. Manzanares Method of Reflexology, Science-based Reflexology Education TM.

5. Manzanares Method of Reflexology, Science-based Reflexology Education TM. About Reflexology.

6. Kay Sally. Reflexology Lymph Drainage.

7. Kay Sally., et al. Camstrand 2012 Research Conference Poster Presentation.

8. Pu-Wei Hou., et al. "The History, Mechanism, and Clinical Application of Auricular Therapy in Traditional Chinese Medicine". Evidence-Based Complementary and Alternative Medicine (2015): 495684.

9. Oleson T. Auriculotherapy manual. Los Angeles, USA: Health Care Alternatives (1996).

10. Bùi Quôc Châu. Le Dien Chan: Méthode originale vietnamienne de multiréflexologie faciale. Paris, France: Editions Grancher (2009).

11. Aguilar Cassarà P. Multireflexology, Face Reflexology, Origin of the Method.

12. Sluter G. "Lone Sorensen's Story”.

13. Sorensen L. "Temprana Reflex Rehabilitation”.

14. Ehinger S. Footage, Newsletter of the Victorian branch of the RAoA (2015).

15. Aguilar Cassarà P and Roca Carrasco A. "Dien Chan - Multireflexology, the original face reflexology method" (2013).

16. Aguilar Cassarà P. FACEASiT.

17. Muller MF. Facial reflexology: A self-care manual. Rochester, Vermont: Healing Arts Press (2003)

18. Sorensen L. Facial Reflexology. New Delhi, India: B. Jain Publishers (P) Ltd (2008).

\section{Assets from publication with us}

- Prompt Acknowledgement after receiving the article

- Thorough Double blinded peer review

- Rapid Publication

- Issue of Publication Certificate

- High visibility of your Published work

Website: $\underline{w w w . a c t a s c i e n t i f i c . c o m / ~}$

Submit Article: www.actascientific.com/submission.php

Email us: editor@actascientific.com

Contact us: +919182824667 